\title{
Effect of Bacillus subtilis Strains on Intestinal Barrier Function and Inflammatory Response
}

\author{
Lamya Rhayat ${ }^{1 *}$, Marc Maresca ${ }^{2}$, Cendrine Nicoletti ${ }^{2}$, Josette Perrier ${ }^{2}$, \\ Karoline Sidelmann Brinch ${ }^{3}$, Sonja Christian ${ }^{3}$, Estelle Devillard ${ }^{1}$ and Erik Eckhardt ${ }^{1}$ \\ ${ }^{1}$ Centre d'Excellence en Recherche Nutritionelle, Adisseo SAS, Malicorne, France, ${ }^{2}$ Aix Marseille Univ., CNRS, Centrale \\ Marseille, iSm2, Marseille, France, ${ }^{3}$ Novozymes A/S, Bagsvaerd, Denmark
}

\section{OPEN ACCESS}

Edited by:

Raquel Hontecillas,

Virginia Tech, United States

Reviewed by:

Michael Kogut,

Agricultural Research Service, United States Department of

Agriculture, United States Claudio Nicoletti,

University of Florence, Italy

${ }^{*}$ Correspondence: Lamya Rhayat

lamya.rhayat@adisseo.com

Specialty section:

This article was submitted to Nutritional Immunology, a section of the journal

Frontiers in Immunology

Received: 29 November 2018 Accepted: 04 March 2019

Published: 29 March 2019

Citation:

Rhayat L, Maresca M, Nicoletti C Perrier J, Brinch KS, Christian S, Devillard E and Eckhardt E (2019) Effect of Bacillus subtilis Strains on Intestinal Barrier Function and Inflammatory Response. Front. Immunol. 10:564. doi: 10.3389/fimmu.2019.00564
Strong tight junctions and curtailed inflammatory responses under stressful conditions are key for optimal digestive health. Bacillus-based probiotics are increasingly being used to maintain broilers' health, but their mode of action is often not well-defined. In the present study we used Caco-2 cells as a model for intestinal epithelia and assessed the effect of three Bacillus-based probiotics on intestinal barrier function and intestinal inflammation. Experimental results showed that one of the three tested strains, Bs 29784, significantly reinforced intestinal barrier integrity under basal conditions through an up-regulation of the expression of tight junction's proteins, whereas the others had no or detrimental effects. When Caco-2 cells were pre-treated with Bacillus subtilis strains, the subsequent IL-8 release to various pro-inflammatory signals (IL-1 $\beta$, deoxynivalenol, or flagellin) was blunted compared to cells that had not been pretreated, but to a different extent depending on the strain of Bacillus used. Bs 29784, was able to significantly decrease IL-8 production in all stressed conditions tested. Mechanistically, Bs 29784 appeared to limit nuclear translocation of NF-kB during IL-1 $\beta$ exposure by preventing IאB degradation. The effects of Bs 29784 were observed independently with supernatant and cells but in a lesser extent than with the combination, indicating that they can thus likely be attributed to both secreted metabolites and cell-associated compounds. Moreover, under inflammatory conditions, Bs 29784 significantly reduced the upregulation of iNOS protein levels further underlining its intestinal anti-inflammatory potential. Our data show that Bacillus-based probiotics may indeed improve digestive health by strengthening intestinal barrier and limiting inflammatory responses and that these properties are strain-dependent.

Keywords: Bacillus subtilis, probiotics, digestive health, intestinal epithelium, inflammation, IL-8, NF-кB, tight junctions

\section{INTRODUCTION}

The intestine presents a large interface with the outside world, which enables efficient absorption of nutrients but also contains large numbers of micro-organisms, including opportunistic pathogens (1). The intestine is also regularly exposed to viruses, toxins, antigenic nutrients, dietary and endogenous surfactants, and other potentially harmful substances that may enter via the diet. A protective layer of mucus, secreted antibodies, and antimicrobial factors greatly reduces exposure of intestinal epithelial cells (IEC) to these threats $(2,3)$ and their translocation across the 
intestinal epithelium is further limited by inter-cellular tight junctions between IEC (4). Temporary weakening of the intestinal barrier may contribute to the development of intestinal inflammatory disorders such as inflammatory bowel disease in humans (5) or necrotic enteritis in broiler chicken $(6,7)$. Since inflammatory cytokines impair gut barrier integrity (8), and intestinal barrier disruption may also promote inflammation, it is important for IEC to limit inflammatory responses and to prevent intestinal barrier disruption.

Interestingly, some pro-inflammatory substances, of which there are many in the intestine, may actually strengthen the intestinal barrier (9) and stimulate expression of anti-microbial factors (3), immunoglobulin-A excreting polymeric Ig receptors (10), or mucin production by Goblet cells (11). Microbial Toll Like Receptor 2 (TLR2) agonists promote tight junction assembly and gene expression (4). Nevertheless, exposure of IEC to microbial compounds such as flagellin, toxins, or cytokines from adjacent cells, can stimulate secretion by IEC of pro-inflammatory cytokines such as interleukin 8 (IL-8) (1214) and weaken tight junctions, thus potentially initiating an inflammatory response.

Many different micro-organisms reside in the intestine or arrive there via the diet. Some species and strains are known to exert pro-inflammatory effects on the intestinal barrier whereas others are anti-inflammatory such as Bacillus (7, 15-20). Due to their anti-inflammatory (and other) properties, many have been introduced as probiotics which, by definition, are live microorganisms that, when ingested, confer a health benefit to the host (21). In animal feed applications, the use of some Bacillus species (B. subtilis, B. amyloliquefaciens, B. licheniformis, or B. pumilus, for example) as probiotics became popular due to their spore-forming properties which makes them easy to handle (16) and to their ability to replace antibiotics as growth promoters (22). Among the different species of Bacillus used as probiotics in poultry, the B. subtilis strain 29784 (Bs 29784) has shown in vivo benefits in broilers, such as improvement of performance parameters under different rearing conditions (23).

In order to evaluate the direct anti-inflammatory potential of $B$. subtilis strains, we used an in vitro cell model. Human colonic epithelial cell lines, such as Caco- 2 cells, are largely used as a model mimicking the intestinal barrier and to investigate the mucosal host response. When grown on permeable supports, Caco- 2 cells polarize and form a monolayer with functionally and morphologically different apical and basolateral surfaces with solid intercellular tight junctions, thus resembling to enterocytes lining the small intestine. Inflammatory responses in Caco-2 cells can be elicited with a variety of relevant stimuli such as the potent activator of Toll-like Receptor 5, flagellin (24), the mycotoxin deoxynivalenol (DON) $(14,25)$, or cytokines such as interleukin 1 beta (IL-1 $\beta$ ). IL-1 $\beta$ is also known to impair tight junctions in Caco-2 cells (26) and stimulates release of pro-inflammatory cytokines IL-6 (27) and IL-8 (12, 28). Since mammals and birds share common mechanisms of digestive health and (mucosal) immunity, express similar chemo- and cytokines, and even have similar microbial communities, it is reasonable to assume that Caco- 2 cells, despite their human origin and with all limitations that this implies, may serve as a model for avian IEC until avian models become available. Thus, we used Caco- 2 cells as a model for the intestinal epithelium to study the effect of the three B. subtilis strains (Bs 29784, Bs A and Bs B) on the barrier integrity and their ability to limit inflammatory responses upon stimulation with various pro-inflammatory substances.

$\mathrm{NF}-\kappa \mathrm{B}$ is well-known to play a central role in regulating gene expression in a wide variety of cellular responses, including immune response and inflammation. In regard to the conditions inducing an inflammatory response used in this study, we targeted the canonical NF-кB signaling pathway in order to shed some light on Bs 29784 mode of action $(29,30)$. In addition to pro-inflammatory cytokines and chemokines, such as IL-8, NF$\kappa \mathrm{B}$ directly induces the upregulation of inducible Nitric Oxide synthase (iNOS) also involved in intestinal inflammation $(31,32)$. Though important for the destruction of bacteria and viruses, NO produced by iNOS may have undesirable effects and needs to be controlled $(33,34)$.

The objective of the present study was to (1) assess in vitro the direct effect of Bs 29784 in induced inflammation conditions, in comparison with two other commercially available B. subtilis strains (Bs A and Bs B) used as probiotics in animal feed, and to (2) investigate how Bs 29874 could intervene in the NF-кB signaling pathway to modulate the inflammatory response.

\section{MATERIALS AND METHODS Bacterial Strains and Cell Cultures}

The bacterial strains used in the study (Bs 29784, Bs A and Bs B) were all commercially available Bacillus subtilis strains used as probiotics in animal feed. For experimental purposes, bacteria were grown from single colonies on Luria-Bertani (LB) plates in $\mathrm{LB}$ broth at $37^{\circ} \mathrm{C}$ overnight with shaking (200 rpm). The next day, overnight cultures were diluted 1:100 in LB broth and left to grow at $37^{\circ} \mathrm{C}$ under agitation $(200 \mathrm{rpm})$ with regular measurement of the optical density $(\mathrm{OD})$ at $600 \mathrm{~nm}$ until $\mathrm{OD}_{600 \mathrm{~nm}}$ reached $0.2-0.3$. Bacteria were then diluted in DMEM without FCS and without antibiotic to obtain the appropriate bacterial density $\left(10^{\mathrm{E} 5}, 10^{\mathrm{E} 6}\right.$, or $10^{\mathrm{E} 7}$ bacteria/ml).

Caco-2 cells (obtained from ATCC) were maintained in Dulbecco's Modified Essential Medium (DMEM) supplemented with $10 \%$ fetal calf serum (FCS), $1 \%$ L-glutamine, and $1 \%$ antibiotics (all from Invitrogen) in a $5 \% \mathrm{CO}_{2}$ incubator, at $37^{\circ} \mathrm{C}$. Prior to each experiment, Caco- 2 cells were seeded at a density of 250,000 cells per $\mathrm{cm}^{2}$ onto Greiner filter inserts ("ThinCert"; $1 \mathrm{~cm}^{2}$; pore size $0.4 \mu \mathrm{m}$ ) and left to differentiate with medium changed every 2 days. After 10-14 days of differentiation, epithelial tightness and cellular differentiation were evaluated by measurement of the transepithelial electrical resistance (TEER) using a Volt/Ohm meter (Millipore). Only tight inserts with a TEER superior or equal to $150 \Omega . \mathrm{cm}^{-2}$ were used experimentally.

\section{Cytokine Release and TEER Measurements}

Bacteria were added in the apical compartment of the Caco-2 cells inserts. Basolateral compartment of the inserts were filled with DMEM without FCS or antibiotics. Inserts were then incubated for $16 \mathrm{~h}$ at $37^{\circ} \mathrm{C}$ in a $5 \% \quad \mathrm{CO}_{2}$ incubator when pro-inflammatory signals were applied. Deoxynivalenol 
(DON, $10 \mu \mathrm{M}$ final concentration, obtained from Romer lab) was added to the apical compartment, while human recombinant IL- $1 \beta \quad(20 \mathrm{ng} / \mathrm{ml}$ final concentration, obtained from Peprotech), or flagellin $(1 \mu \mathrm{g} / \mathrm{ml}$ final concentration, extracted from Salmonella typhimurium, obtained from Invivogen) were added basolaterally to Caco-2. Epigallocatechin gallate (EGCG, $10 \mu \mathrm{M}$ final concentration, obtained from Sigma Aldrich) was added to the apical compartment and used as positive anti-inflammatory control. After $6 \mathrm{~h}$ at $37^{\circ} \mathrm{C}$, basolateral media were collected and stored at $-80^{\circ} \mathrm{C}$ before IL-8 cytokine measurement by ELISA (BD Biosciences) was performed. TEER was measured using a Volt/Ohm meter (Millipore).

\section{Analysis of NF-кB Signaling Pathway Activation}

The effect of bacteria on NF- $\kappa$ B signaling pathway was performed as previously described $(35,36)$. Briefly, Caco- 2 cells seeded onto inserts were incubated with bacteria for $16 \mathrm{~h}$ at $37^{\circ} \mathrm{C}$. At the end of the incubation, cells exposed or not to bacteria were stimulated basolaterally with human recombinant IL-1 $\beta$ (20 ng/ml final concentration, from Peprotech) for $0,15,30$, or $60 \mathrm{~min}$ at $37^{\circ} \mathrm{C}$. Nuclear and cytosolic fractions were then extracted. Briefly, cells were washed 3 times with cold phosphate buffer saline (PBS), scraped into cold PBS before resuspension in a buffer containing $10 \mathrm{mM}$ Hepes ( $\mathrm{pH} 7.8,10 \mathrm{mM} \mathrm{KCl,} 2 \mathrm{mM}$ $\mathrm{MgCl}_{2}, 0.1 \mathrm{mM}$ EDTA, $1 \mathrm{mM}$ DTT, $1.25 \mathrm{mM}$ NaF, 1 mM NaVO4, $1 \mathrm{mM}$ PMSF) and incubated on ice for $15 \mathrm{~min}$. Nonidet P-40 ( $0.5 \%$ final concentration) was then added. The obtained mixture was vortexed for $15 \mathrm{~s}$ prior to centrifugation $\left(13,000 \mathrm{~g}, 4^{\circ} \mathrm{C}\right.$, $30 \mathrm{~s})$ to pellet nuclei. The soluble supernatants corresponding to cytosolic fractions were resuspended in Laemmli sample buffer. The pelleted nuclei were resuspended in a buffer containing $50 \mathrm{mM}$ Hepes ( $\mathrm{pH} 7.8,50 \mathrm{mM} \mathrm{KCl,} 300 \mathrm{mM} \mathrm{NaCl}$, $10 \%$ glycerol, $0.1 \mathrm{mM}$ EDTA, $1 \mathrm{mM}$ DTT, $0.2 \mathrm{mM} \mathrm{NaF}, 0.2 \mathrm{mM}$ $\mathrm{NaVO} 4,1 \mathrm{mM}$ PMSF) and agitated for $20 \mathrm{~min}$ at $4^{\circ} \mathrm{C}$ (briefly vortexed every $5 \mathrm{~min}$ ). The samples were finally centrifuged $\left(13,000 \mathrm{~g}, 4^{\circ} \mathrm{C}, 5 \mathrm{~min}\right)$ and supernatants containing nuclear proteins were resuspended in Laemmli sample buffer. Samples were boiled for $10 \mathrm{~min}$ and analyzed by Western blotting. To this end, nuclear and cytosolic samples were separated on 4$12 \%$ precast SDS-PAGE gels (ThermoFisher) before transfer onto a nitrocellulose membrane. The membrane was then incubated for $1 \mathrm{~h}$ at room temperature in PBS containing 2\% bovine serum albumin, washed with PBS containing Tween-20 at $0.05 \%$, and incubated overnight at $4^{\circ} \mathrm{C}$ with the appropriate primary antibody diluted in PBS supplemented with $2 \%$ bovine serum albumin as per manufacturer's suggestions (i.e., 1:1,000 dilution). Rabbit monoclonal antibody against human NF-кB/p65 (C22B4)

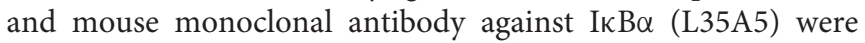
obtained from Cell Signaling Technology. Membranes were washed 3 times with PBS and incubated for $1 \mathrm{~h}$ with alkaline phosphatase-conjugated goat-anti-rabbit (for NF- $\mathrm{B} / \mathrm{p} 65$ ) or anti-mouse (for $I \kappa B \alpha$ ) immunoglobulin $G$ secondary antibodies (Sigma Aldrich). Membranes were finally washed extensively with PBS Tween-20 and developed with alkaline phosphatase substrate (NBT/BCIP, Pierce). Band densities were measured using Image J software.

\section{Incubation of Caco-2 Cells With Secreted and Cell-Associated Bacterial Factors}

To evaluate the impact of Bs 29784 secreted factors (SF) on the immune response, Caco-2 cells seeded onto $1 \mathrm{~cm}^{2}$ inserts (12-well inserts; pore size $0.4 \mu \mathrm{m}$ ) were exposed to live bacteria (initial bacterial density of $10^{7}$ bacteria/ml) on top of a $0.3 \mathrm{~cm}^{2}$ insert (24-well inserts, pore size $0.4 \mu \mathrm{m}$ ). This insert was positioned in the apical compartment of the Caco-2 insert, thus preventing direct contact between bacteria and Caco- 2 cells. After $16 \mathrm{~h}$ at $37^{\circ} \mathrm{C}$, Caco- 2 cells were then stimulated with IL- $1 \beta$ or with a mixture of human recombinant pro-inflammatory cytokines called Cytomix (IFN$\gamma$ at $2,000 \mathrm{U} / \mathrm{ml}$ final concentration, TNF- $\alpha$ at $100 \mathrm{ng} / \mathrm{ml}$ final concentration, and IL- $1 \beta$ at $20 \mathrm{ng} / \mathrm{ml}$ final concentration, all purchased from PeproTech). Concerning the cell-associated factors (CAF), Caco-2 cells seeded onto $1 \mathrm{~cm}^{2}$ inserts were exposed to paraformaldehyde (PFA)-killed bacteria. Briefly, these bacteria were grown in LB broth to reach $0.6 \mathrm{OD}_{600 \mathrm{~nm}}$, washed with PBS, and then killed by $30 \mathrm{~min}$ exposure to PFA (4\% final concentration). Bacteria were then washed three times with PBS and resuspended in DMEM to reach a bacterial density equivalent to $10^{\mathrm{E} 9}$ bacteria/ml. Killing of bacteria was confirmed by the absence of colonies on LB agar plates. Caco- 2 cells were finally exposed for $16 \mathrm{~h}$ at $37^{\circ} \mathrm{C}$ to killed bacteria before stimulation with IL-1 $\beta$ or Cytomix.

\section{iNOS Western Blotting}

The effect of bacteria on the induction of iNOS by proinflammatory cytokines was also evaluated as previously described $(33,34)$. Briefly, Caco-2 cells seeded onto inserts were incubated with bacteria for $16 \mathrm{~h}$ at $37^{\circ} \mathrm{C}$. At the end of the incubation, Caco- 2 cells were basolaterally exposed to Cytomix (IFN- $\gamma$ at $2,000 \mathrm{U} / \mathrm{ml}$ final concentration, TNF- $\alpha$ at $100 \mathrm{ng} / \mathrm{ml}$ final concentration, and IL- $1 \beta$ at $20 \mathrm{ng} / \mathrm{ml}$ final concentration, all purchased from PeproTech). iNOS protein levels were then measured as previously described $(34,37)$. After $24 \mathrm{~h}$ of incubation, cells were washed with cold PBS and solubilized on ice with $100 \mu \mathrm{l}$ of lysis buffer (1\% Triton X100 in cold PBS) containing a protease inhibitor cocktail (from Sigma Aldrich). Protein concentrations were determined with the Bradford Reagent (Sigma Aldrich) following the manufacturer's instructions. Twenty-five microliter of 5X Laemmli sample buffer were added and samples boiled for $10 \mathrm{~min}$. Samples containing 50 $\mu \mathrm{g}$ of protein were separated on $4-12 \%$ precast SDS-PAGE gels (ThermoFisher) before transfer to a nitrocellulose membrane. The membrane was incubated for $1 \mathrm{~h}$ at room temperature in PBS containing $2 \%$ bovine serum albumin, washed with PBS, and incubated for $1 \mathrm{~h}$ with the appropriate primary antibody diluted in PBS as per manufacturer's suggestions (i.e., 1:100 dilution). Rabbit polyclonal antibodies against human iNOS (sc-651) and actin (A-2066) were obtained from Santa Cruz and Sigma Aldrich, respectively. Membranes were then washed 3 times with PBS containing Tween-20 at $0.05 \%$ and 
incubated for $1 \mathrm{~h}$ with alkaline phosphatase-conjugated goat antirabbit immunoglobulin G secondary antibody (Sigma Aldrich). Membranes were finally washed at least three times with PBS Tween-20 and revealed with alkaline phosphatase substrate (NBT/BCIP, Pierce). Band densities were measured using Image J software and iNOS levels being normalized to actin staining.

\section{Tight Junction Proteins Western Blotting}

The effect of bacteria on the expression of tight junction proteins was evaluated using Western-blot. Briefly, Caco-2 cells seeded onto inserts were left untreated (control) or were treated apically with Bs 29784 (initial bacterial density of $10^{7}$ bacteria/ml) or with $\mathrm{DON}$ at $100 \mu \mathrm{M}$ for $16 \mathrm{~h}$ at $37^{\circ} \mathrm{C}$. At the end of the incubation, Caco-2 cells were washed three times with cold PBS and solubilized on ice with $100 \mu$ l of lysis buffer (1\% Triton X-100 in cold PBS) containing a protease inhibitor cocktail (from Sigma Aldrich). Protein concentrations were determined with the Bradford Reagent (Sigma Aldrich) following the manufacturer's instructions. Twenty-five microliter of $5 \mathrm{X}$ Laemmli sample buffer were added and samples boiled for $10 \mathrm{~min}$. Samples containing $50 \mu \mathrm{g}$ of protein were separated on $4-12 \%$ precast SDS-PAGE gels (ThermoFisher) before transfer to a nitrocellulose membrane. The membrane was incubated for $1 \mathrm{~h}$ at room temperature in PBS containing 2\% bovine serum albumin, washed with PBS, and then incubated with the appropriate primary antibody diluted in PBS as per manufacturer's suggestions (i.e., 1:100 dilution). Antibodies used were rabbit polyclonal antibodies against ZO-1 (ThermoFisher, reference 40-2200) or Occludin (ThermoFisher, reference 40-6100) and mice monoclonal antibody against Claudin1 (ThermoFisher, reference 37-4900). After $1 \mathrm{~h}$, membranes were washed 3 times with PBS containing Tween-20 at $0.05 \%$ and incubated for $1 \mathrm{~h}$ with alkaline phosphatase-conjugated goat anti-rabbit immunoglobulin G secondary antibody (Sigma Aldrich). Membranes were finally washed three times with PBS Tween-20 and revealed with alkaline phosphatase substrate (NBT/BCIP, Pierce). Band densities were measured using Image J software and levels of expression of tight junction proteins were normalized using actin staining.

\section{Statistical Analysis}

Raw data from IL-8 measurement assays were subjected to ANOVA procedure of XLSTAT, with treatment as fixed effects. Results are reported as least square means with bars representing the standard error of the mean (SEM). LS means were assumed statistically different at $P \leq 0.05$.

A two-tailed $t$-test was used to compare groups in Western blotting assays. Results are reported as least square means with bars representing the standard deviation (SD). LS means were assumed statistically different at $P \leq 0.05$.

\section{RESULTS}

\section{Effects on TEER Are Strain Specific}

Growth of the three B. subtilis strains in culture media being similar, we used the same concentration of each, allowing us a direct comparison between the strains (results not shown). Preliminary tests had shown that the three strains had a dosedependent effect on TEER, with a maximal effect at $10^{7} \mathrm{CFU} / \mathrm{ml}$. Therefore, this dose was chosen for future experiments. When Caco-2 cells were apically exposed for $16 \mathrm{~h}$ with the various strains, subsequent TEER measurements showed that the three $B$. subtilis strains behaved differently (Figure 1). In this experiment, we used Epigallo Catechin Gallate (EGCG) -an established antiinflammatory compound (38) as positive control. As expected,

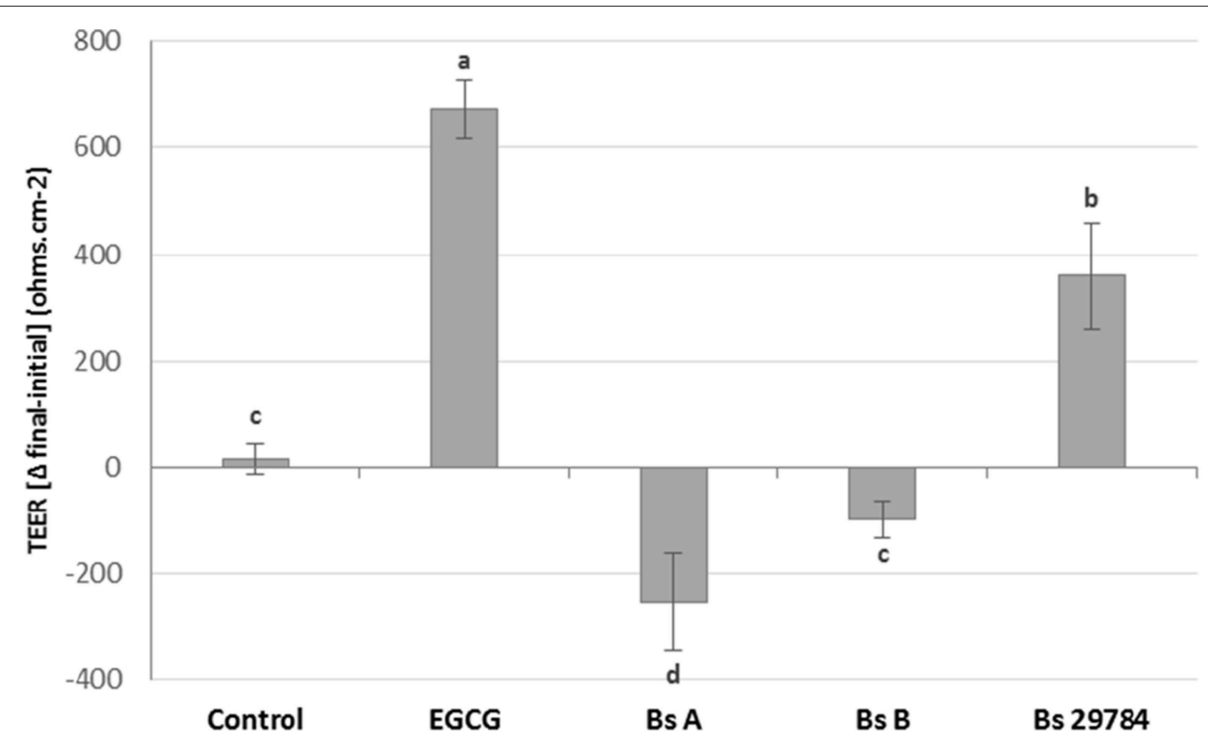

FIGURE 1 | Effect of different Bacillus strains on TEER of differentiated Caco-2 cells. These cells had been exposed for $16 \mathrm{~h}$ on their apical surface with the indicated strains $\left(10^{7} \mathrm{CFU} / \mathrm{ml}\right)$ or with EGCG $(10 \mu \mathrm{M})$ prior to TEER measurement. Results are expressed as difference between final vs. initial TEER. Labeled means without a common letter differ, $p<0.05$. 
EGCG significantly $(p<0.001)$ increased the TEER $(p<0.001)$, thus validating the experiment. Whereas, Bs 29784 caused a significant increase in TEER of 50.7\% $(p<0.001)$ compared to the unstimulated control, Bs B had no significant effect ( $p=$ 0.107 ), while Bs A caused a significant decrease in TEER of about $40 \%(p<0.01)$. The increase in TEER caused by Bs 29784 was correlated to an increase in the expression of the main proteins involved in the formation of tight junctions (Figure 2). Thus, whereas exposure to DON is associated to a decrease in the expression of ZO-1, occludin and claudin-1 (i.e., 40.3, 27, and $39.1 \%$ decrease, respectively) Bs 29784 caused an increase in their expression (i.e., 82.9, 110.2, and 43.9\% increase in ZO-1, occludin and claudin-1 expression, respectively).

\section{Immunomodulatory Properties Are Strain Specific}

We next evaluated the effect of the three B. subtilis strains on intestinal inflammation by measuring basolateral release of IL8 from Caco- 2 cells exposed apically to Bacillus for $16 \mathrm{~h}$ prior to stimulation for $6 \mathrm{~h}$ with various pro-inflammatory compounds: IL1- $\beta$, Deoxynivalenol (DON) and flagellin (Fla) (Figure 3). EGCG was here again used as an anti-inflammatory control. IL- 8 release by Caco- 2 cells was increased by all three stimuli. EGCG pretreatment decreased IL-8 release induced in all stressed conditions. Not unexpectedly, all B. subtilis strains by themselves stimulated IL-8 production. However, all tested strains were able to attenuate IL- $1 \beta$-induced IL- 8 production by $61.3,65.3$, and $74.8 \%$ with Bs A, Bs B, and Bs 29784, respectively, compared to Caco-2 cells with no pre-treatment (Figure 3A). Nevertheless, the strongest anti-inflammatory effect in this condition was obtained with Bs 29784 when compared to the two other $B$. subtilis strains. In flagellin-mediated inflammation, we observed that Bs A caused a $14.9 \%$ increase $(p<0.01)$ in IL-8 release, whereas Bs B and Bs 29784 decreased it by $56.1 \%(p<0.0001)$ and $38.2 \%(<0.0001)$, respectively (Figure 3B). Interestingly, Bs A and Bs B actually potentiated the effect of DON on IL-8 production $(+139.0$ and $+97.7 \%$, respectively), whereas Bs 29784 reduced IL-8 production by $46.4 \%(p<0.0001)$ compared to DON-treated control (Figure 3C). Together, these results further illustrate the differences between Bacillus strains. Since Bs 29784 showed a significant decrease in IL-8 release in all inflammatory conditions, we subsequently investigated this strain in more detail.

\section{Protective Effects of Bs 29784 Involve Inhibition of the NF-кB Nuclear Translocation in IL-1 $\beta$ Stressed Conditions}

A key step in many inflammatory processes is the translocation of transcription factor $\mathrm{NF}-\kappa \mathrm{B}$ from the cytosol into the nucleus, where it drives the expression of pro-inflammatory cytokines including IL-8. Indeed, we observed an increase in the amount of NF- $\mathrm{B} / \mathrm{p} 65$ in the nucleus of Caco-2 cells stimulated with IL-1 $\beta$ (Figures 4A,B; 5.5-, 4.8-, and 4.1-fold increase compared to initial nuclear signal after 15, 30 and $60 \mathrm{~min}$, respectively). However, when the Caco- 2 cells had been pre-incubated for $16 \mathrm{~h}$ with Bs 29784 , IL-1 $\beta$-induced nuclear

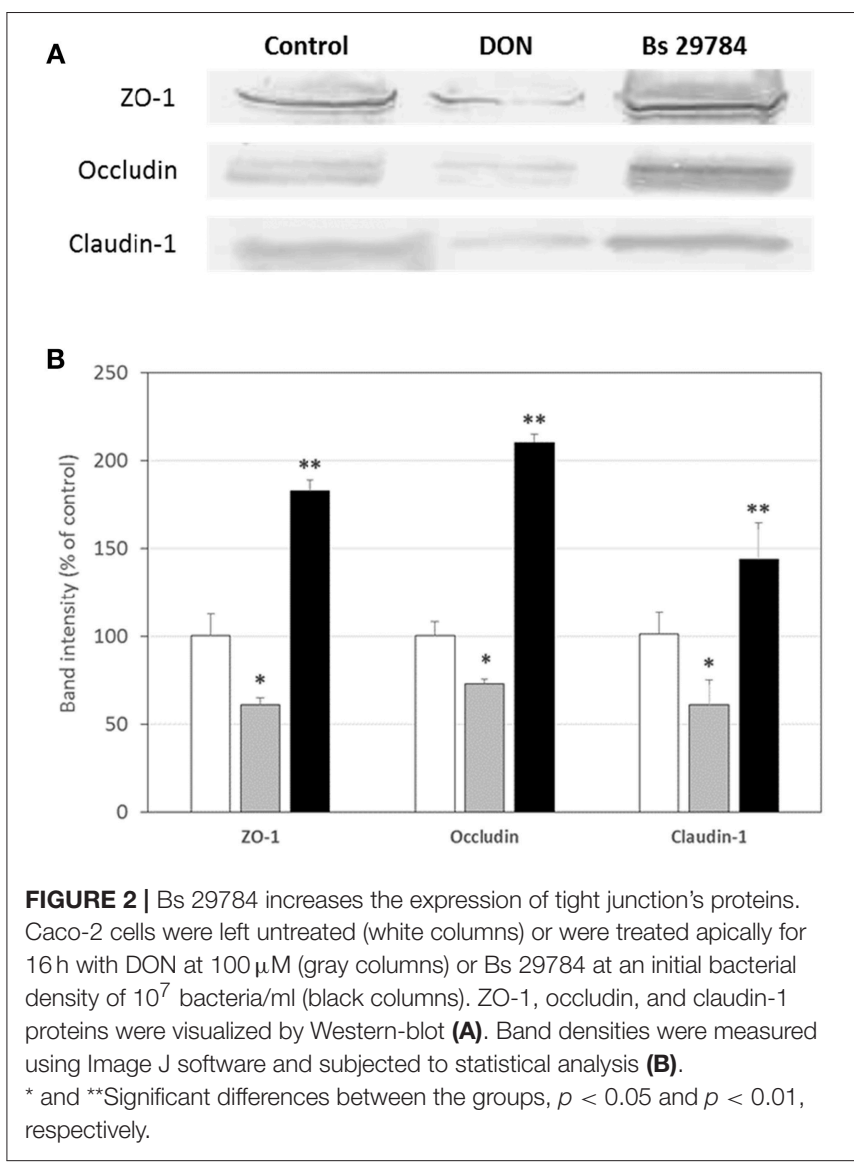

translocation of NF- $\kappa \mathrm{B} / \mathrm{p} 65$ was prevented (0.76-, 1.17-, and 1.09fold increase compared to initial nuclear signal after 15, 30, and $60 \mathrm{~min}$, respectively).

Nuclear translocation of $\mathrm{NF}-\kappa \mathrm{B} / \mathrm{p} 65$ is prevented by binding to cytosolic $\mathrm{I} \kappa \mathrm{B} \alpha$, and its release requires proteasome-mediated

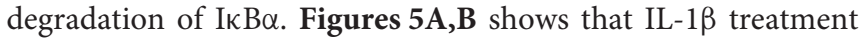
of Caco- 2 cells caused a rapid and significant $(p<0.01$ and 0.05 ) degradation of I $\mathrm{B} \alpha$ after 15 and $30 \mathrm{~min}$ (17.2 and $36.7 \%$ of control signal, respectively) but a rebound at $60 \mathrm{~min}$, due to the fact that $\mathrm{I} \kappa \mathrm{B} \alpha$ expression itself is NF- $\kappa \mathrm{B}$ dependent (35). Interestingly, pretreatment of Caco-2 cells with Bs 29784 prevented IL- $1 \beta$ from causing significant I $\kappa \mathrm{B} \alpha$ degradation [94.9, 92.2, and 142.1\%, $(p<0.05)$, of control signal, after 15, 30, and $60 \mathrm{~min}$ of IL-1 $\beta$ exposure, respectively] suggesting that Bs 29784 has a positive effect on the modulation of the inflammatory response by inhibiting the degradation of $I \kappa B \alpha$.

\section{Protective Effect of Bs 29784 Involve Secreted and Cell-Associated Factor(s)}

We next evaluated the nature of the bacterial factors that exert the observed immunomodulatory effects by Bs 29784 in IL-1 $\beta$ stimulated Caco-2 cells. Caco-2 cells were thus exposed to Bs 29784 secreted factors (SF) or to PFA-killed Bs 29784 (also noted as cell-associated factors, CAF). As shown in Figure 6, both SF and CAF, were able to reduce IL- 8 secretion upon stimulation with IL-1 $\beta$ (59.2 and $67.3 \%$ of inhibition $(p<0.01)$, respectively, 


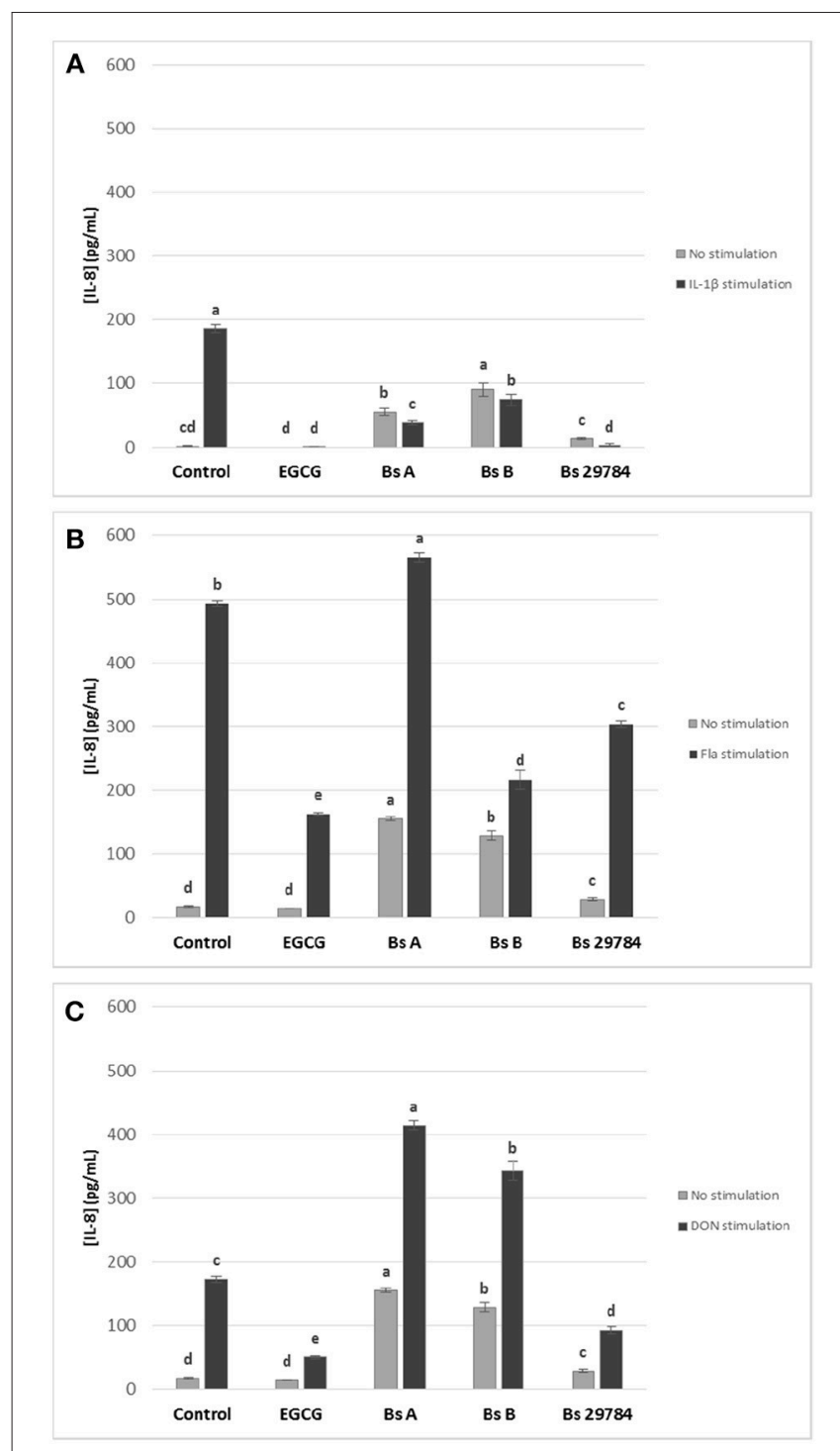

FIGURE 3 | Effect of apical application for $16 \mathrm{~h}$ of different $B$. subtilis strains on IL-8 release of Caco-2 cells with or without subsequent $6 \mathrm{~h}$ basolateral stimulation with (A) IL-1 $\beta(20 \mathrm{ng} / \mathrm{ml})$ or (B) flagellin $(1 \mu \mathrm{g} / \mathrm{ml})$, or (C) apical stimulation with DON $(10 \mu \mathrm{M})$. EGCG was used as positive control. Labeled means without a common letter differ within each condition, $p<0.05$.

compared to IL-1 $\beta$-treated control). However, compared to live Bs 29784 causing $93.3 \%$ of inhibition $(p<0.001)$, their protective effect was reduced. This indicates that both Bs 29784 cells and its secreted compounds are involved in the control of IL8 production.

\section{Bs 29784 Reduces Induction of iNOS by Pro-inflammatory Cytokines}

Thereafter, we evaluated if Bs 29784 was able to limit the NF$\kappa \mathrm{B}$ dependent induction of iNOS in simulated inflammatory conditions. Caco-2 cells pre-treated with or without Bs 29784 were exposed to a mixture of pro-inflammatory cytokines (IFN $\gamma$, $\mathrm{TNF} \alpha$, and IL-1 $\beta$ ) called Cytomix before analysis of iNOS

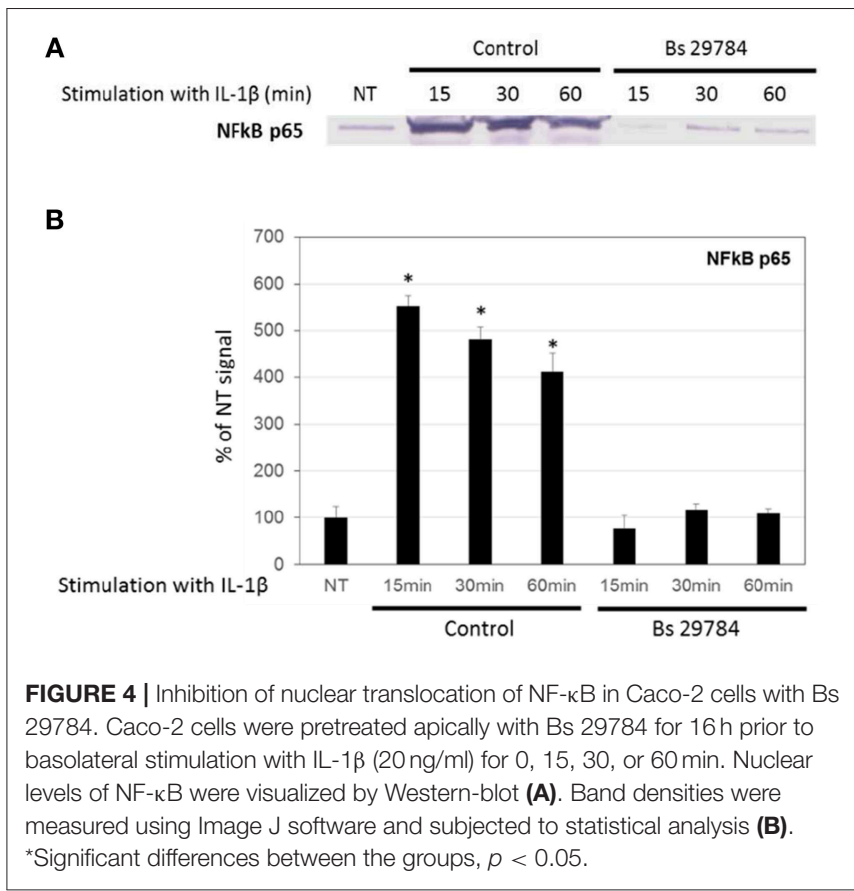

A

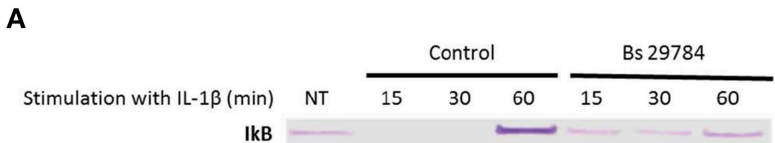

B

$$
\text { IkB }
$$

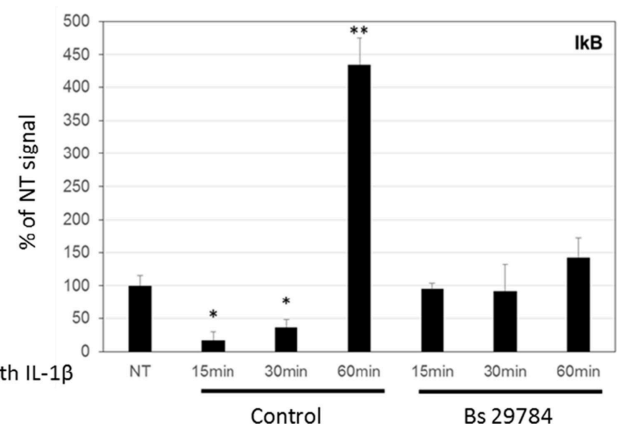

FIGURE 5 | Bs 29784 prevents the breakdown of the NF-кB inhibitor, ІкB $\alpha$. Caco-2 cells were pretreated apically with Bs 29784 for $16 \mathrm{~h}$ prior to basolateral stimulation with $\mathrm{L}-1 \beta(20 \mathrm{ng} / \mathrm{ml})$ for $0,15,30$, or $60 \mathrm{~min}$. Cytolosic levels of $I_{\kappa} B \alpha$ were visualized by Western-blot (A). Band densities were measured using Image $\mathrm{J}$ software and subjected to statistical analysis (B). ${ }^{*}$ and ${ }^{* *}$ Significant differences between the groups, $p<0.05$ and $p<0.01$, respectively.

expression by Western-blot. Results (Figure 7) demonstrated that live Bs 29784 bacteria were able to inhibit Cytomixmediated induction of iNOS $57.7 \%$ of inhibition compared to cytomix-treated cells, $p<0.01)$. SF and CAF were also tested and displayed moderate activity compared to live bacteria [28.3 and $31.2 \%$ of inhibition compared to cytomixtreated cells, for secreted factor(s) and PFA-killed bacteria, respectively, $p<0.05$ ], indicating that here also, Bs 29784 cells and its secreted compounds are involved in regulation of iNOS induction. 


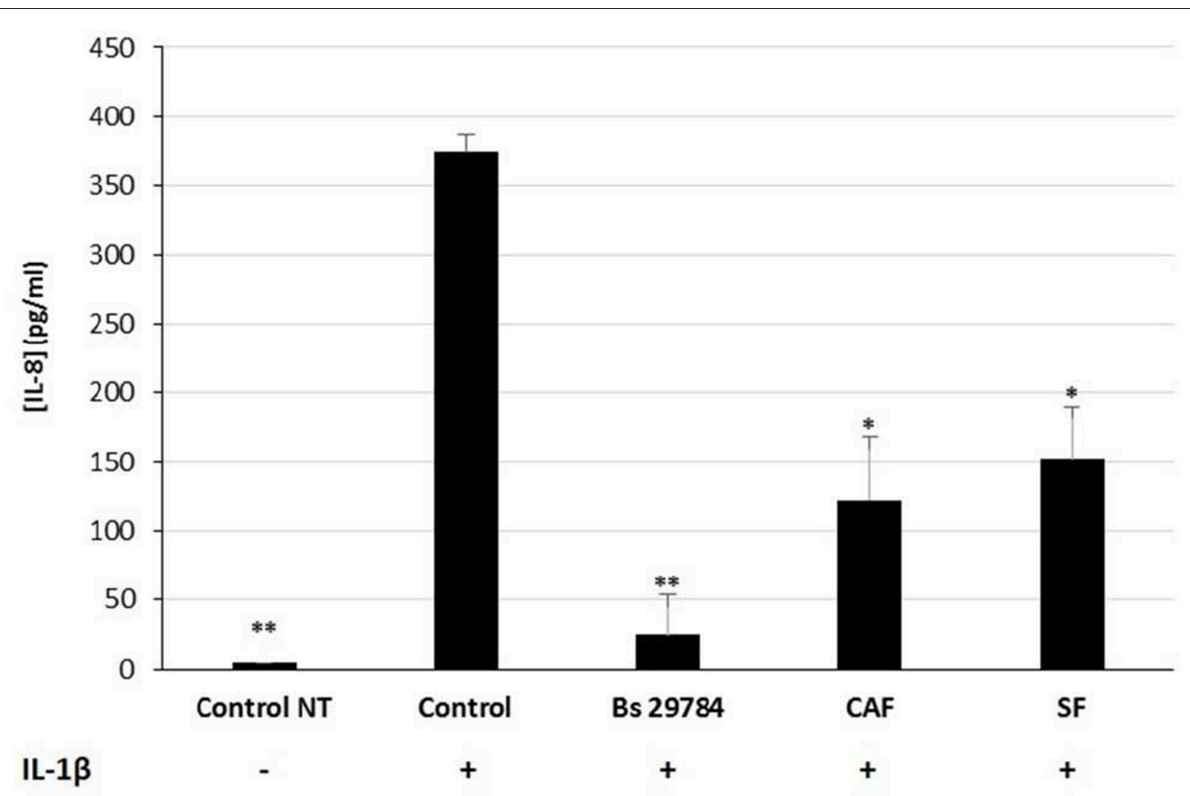

FIGURE 6 | Contribution of soluble and membrane-bound factors to anti-inflammatory effects of Bs 29784. Caco-2 cells were pretreated apically either with live secreting cells (Bs 29784), with PFA-killed Bs 29784 (Cell Associated Factors, CAF) or with Bs 29784 physically separated from the Caco-2 cells by an additional filter (Secreted Factors, SF). After $16 \mathrm{~h}$, the cells were treated basolaterally with IL-1 $13(20 \mathrm{ng} / \mathrm{ml})$ and IL-8 released in the next $6 \mathrm{~h}$ was measured by ELISA.

* and ${ }^{* *}$ Significant differences between the groups, $p<0.05$ and $p<0.01$, respectively.
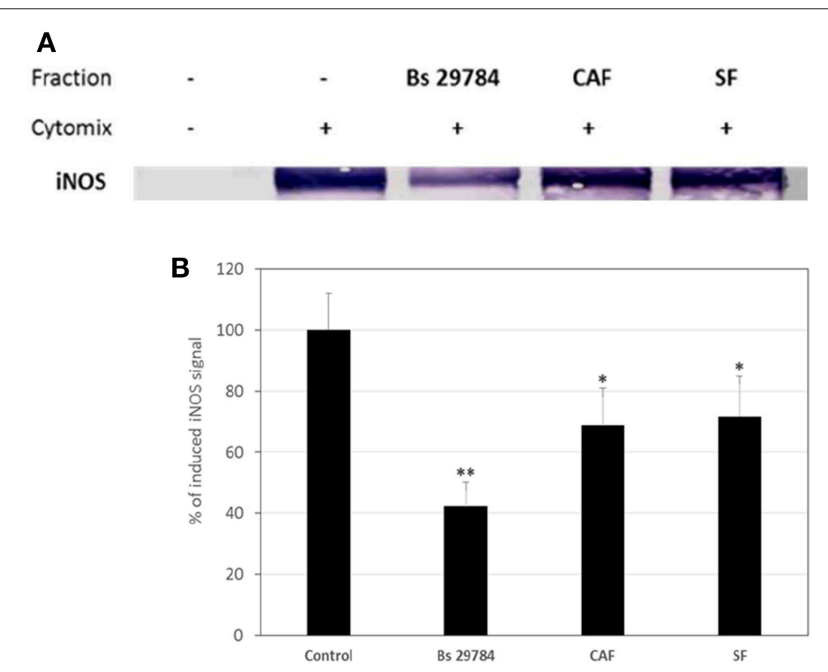

FIGURE 7 | Blunted cytokine-induced upregulation of iNOS due to pretreatment of cells with Bs 29784. Caco-2 cells were pretreated with Bs 29784: live secreting cells (Bs 29784), PFA-killed cells (CAF), or secreted factors from BS 29784 (SF), or not, and subsequently stimulated basolaterally with Cytomix for $24 \mathrm{~h}$. Cytolosic levels of iNOS were visualized by Western-blot (A). Band densities were measured using Image $\mathrm{J}$ software and subjected to statistical analysis (B). * and **Significant differences between the groups, $p<0.05$ and $p<0.01$, respectively.

\section{DISCUSSION}

The intestine absorbs food with great efficiency, and is also armed with a large amount of immune cells ready to intervene when micro-organisms from the large local microbiome breach the intestinal epithelium. In fact, intestinal epithelial barrier is one of the major defense mechanisms against invasion. Nutritional or pharmacological interventions aimed at reinforcing this barrier are being actively sought after for human and animal health.

In the livestock industry, where the prophylactic and growthpromoting use of antibiotics is being restricted in more and more countries, an increasing number of ingredients is being developed to protect digestive health and prevent increased leakiness of the gut and increased intestinal inflammation (39). Probiotics, also referred to as Direct-Fed Micro-organisms, are an attractive group of ingredients, and some have shown promising effects on gut barrier function, associated gains in health, such as the control of the inflammatory response, and productivity. Bacillus-based probiotics are especially popular due to the fact that they can be formulated as stable spores and can be therefore be used in processed feed. However, the mode of action of many Bacillus species and strains used as feed additive is not well-understood.

In the present study, we first tested how three B. subtilis strains affected intestinal-epithelial integrity. Surprisingly, we found that only Bs 29784 actually strengthened barrier function as reflected by increased trans-epithelial potential differences (Figure 1). In contrast to Bs 29784, Bs B had no effect, and Bs A weakened epithelial resistance, indicating a deleterious effect on barrier integrity. The effect of Bs 29784 on TEER was associated to an increase in the expression of the main proteins involved in tight junctions, i.e., ZO-1, occluding, and claudin-1 (Figure 2) in accordance with previously published results obtained with the porcine intestinal cells IPEC-J2 (40).

One reason of focusing on intestinal epithelial cells is that probiotics likely mainly interact directly with these cells, and 
another is that these cells are increasingly being recognized as regulators of inflammation beyond their absorptive role. Indeed, Intestinal Epithelial Cells (IEC) secrete a variety of cytokines and chemokines (41), which orchestrate immune responses and regulate the recruitment of immune cells. One such chemokine is IL-8, which mainly attracts neutrophils and thus, increases local inflammatory response. Since the $B$. subtilis strains differentially affected TEER we next explored their possible immunomodulatory effects and tested if and how they are able to regulate inflammatory processes in Caco- 2 cells. Our results showed again that the effect of Bacillus on IL-8 secretion by IEC is rather strain-specific.

When we tested the immunomodulatory effects of the three Bacillus strains, we first noticed that strains themselves slightly stimulated IL-8 release by IEC (Figure 3) which is in line with previous studies reporting a mild stimulation of IL- 8 release from Caco-2 cells with Bacillus strains probiotic (42). Nevertheless, the magnitude of IL- 8 secretion was different between the three strains, with Bs 29784 being the weakest stimulator. When cells pre-treated with $B$. subtilis were subsequently challenged with different, potent pro-inflammatory molecules, it was observed that the IEC produced significantly less IL- 8 , suggesting that the treatment with bacterial strains had programmed the cell to cause a milder inflammatory response. One benefit of this attenuating effect could be that these strains could be useful in limiting inflammatory responses during intestinal injury or when intestinal macrophages fail to downregulate IL-1 $\beta$ production during chronic intestinal inflammation (43).

Interestingly, Bs 29784 exhibited a stronger anti-inflammatory effect than the two other strains tested. Bs 29784 also exerted its immunomodulatory property in all stressed conditions used here, whereas Bs A and Bs B strains potentiated the proinflammatory effect of DON and Bs A also potentiated the pro-inflammatory effect of flagellin.

The mechanistics behind these discrepant effects are not clear. Of all three B. subtilis strains tested, it thus seemed that Bs 29784 was the most potent modulator of inflammatory responses. To gain insight into the mechanism, we tested, in IL- $1 \beta$ stimulated conditions, whether Bs 29784 limits the translocation of NF$\kappa \mathrm{B}$ from the cytosol into the nucleus. Indeed, while initially stimulating nuclear translocation of NF- $\kappa \mathrm{B}$ to a small extent (in agreement with the observed slight stimulation of IL- 8 release), Bs 29784 strongly inhibited the IL- $1 \beta$ dependent translocation of NF- $\kappa$ B into the nucleus (Figure 4). Conversely, I $\mathrm{B}$, a molecule that inhibits NF- $\kappa$ B translocation, did not decrease in Bs 29784 pre-treated Caco- 2 cells after IL-1 $\beta$ challenge (Figure 5).

Previous studies demonstrated an immunomodulatory effect of bacterial soluble compounds, some of which act by inhibiting the NF- $\kappa \mathrm{B}$ signaling pathway, or of bacterial membraneassociated compounds, but rarely both (44-48). Interestingly, the protective effect of Bs 29784 can likely be attributed to the cells themselves and to the secreted compounds since, both of these were able to exert an anti-inflammatory effect that was lower than that of the combination (Figure 6).

The use of Caco-2 cells may, in some respects, seem too remote from the context in which the Bs 29784 strain is used.
However, in the absence of a clearly established avian in vitro model, it constitutes a first step that allowed us to demonstrate the direct immunomodulatory potential of Bs 29784. Beyond this direct effect shown in this study, we must also consider the indirect effect of Bs 29784, by acting on the microbiota through the compounds it secretes. Identifying them would shed light on the mode of action of this probiotic strain which we already have shown to have an impact on the animal microbiota (49).

Our results indicate that $B$. subtilis-based probiotics help control the release of IL- 8 by IEC in response to several proinflammatory stimuli. We did not measure other cytokines, but obtained additional evidence of an anti-inflammatory effect, namely the reduction of NF- $\mathrm{B}$ dependent iNOS upregulation upon exposure to pro-inflammatory cytokines (Figure 7) likely due to the sequestration of NF- $\mathrm{B}$ in the cytosol. iNOS is able to produce large amounts of NO, which helps destruct pathogens, but may be harmful if uncontrolled $(33,34)$. Therefore, iNOS expression should not be completely inhibited but tightly regulated, as Bs 29784 seems to do, to prevent excessive inflammation.

Taken together, our results show that B. subtilis-based probiotics do possess properties that may help attenuate and prevent inflammatory responses in the intestine while also strengthening the gut barrier; a key property that helps prevent potentially sustaining chronic inflammation. In this respect, we speculate that the growth-promoting effect of Bs 29784, previously shown in poultry (23), could be explained in part by an immune modulating action created by a combination of metabolites and membrane-bound factors. Similar protective effects of $B$. subtilis strains were already observed, in other systems, including in vivo models (50-53). However, the results also show that not all $B$. subtilis strains supports these effects equally and that important differences may exist in the efficacy which these promising feed and food additives may act positively in inflammatory challenged conditions and promote gut health.

\section{DATA AVAILABILITY}

The datasets generated for this study are available on request to the corresponding author.

\section{AUTHOR CONTRIBUTIONS}

LR, ED, and MM designed the experimental strategy. MM, $\mathrm{CN}$, and JP performed the experiments. $\mathrm{MM}$ and $\mathrm{LR}$ analyzed the experimental data. MM, EE, and LR wrote the manuscript. All authors revised and approved the final manuscript.

\section{FUNDING}

LR, EE, and ED were employed by Adisseo France SAS. KB and SC were employed by Novozymes A/S. MM, CN, and JP were employed by CNRS. The authors declare that, this study was entirely funded by Adisseo France SAS. 


\section{REFERENCES}

1. Sommer F, Bäckhed F. The gut microbiota-masters of host development and physiology. Nat Rev Microbiol. (2013) 11:227-38. doi: 10.1038/nrmicro2974

2. Peterson LW, Artis D. Intestinal epithelial cells: regulators of barrier function and immune homeostasis. Nat Rev Immunol. (2014) 14:141-53. doi: $10.1038 /$ nri3608

3. Mukherjee S, Hooper LV. Antimicrobial defense of the intestine. Immunity. (2015) 42:28-39. doi: 10.1016/j.immuni.2014.12.028

4. Ulluwishewa D, Anderson RC, McNabb WC, Moughan PJ, Wells JM, Roy NC. Regulation of tight junction permeability by intestinal bacteria and dietary components. J Nutr. (2011) 141:769-76. doi: 10.3945/jn.110.135657

5. Zeissig S, Bürgel N, Günzel D, Richter J, Mankertz J, Wahnschaffe U, et al. Changes in expression and distribution of claudin 2, 5 and 8 lead to discontinuous tight junctions and barrier dysfunction in active Crohn's disease. Gut. (2007) 56:61-72. doi: 10.1136/gut.2006.094375

6. Antonissen G, van Immerseel F, Pasmans F, Ducatelle R, Haesebrouck F, Timbermont L, et al. The mycotoxin deoxynivalenol predisposes for the development of Clostridium perfringens-induced necrotic enteritis in broiler chickens. PLOS ONE. (2014) 9:e108775. doi: 10.1371/journal.pone.0108775

7. Eichner M, Augustin C, Fromm A, Piontek A, Walther W, Bücker R, et al. In colon epithelia, Clostridium perfringens enterotoxin causes focal leaks by targeting claudins which are apically accessible due to tight junction derangement. J Infect Dis. (2017) 217:147-57. doi: 10.1093/infdis/jix485

8. Capaldo CT, Nusrat A. Cytokine regulation of tight junctions. Biochimica et biophysica acta. (2009) 1788:864-71. doi: 10.1016/j.bbamem.2008.08.027

9. Pasparakis M. IKK/NF-kappaB signaling in intestinal epithelial cells controls immune homeostasis in the gut. Mucosal Immunol. (2008) 1(Suppl.)1:S54-7. doi: $10.1038 / \mathrm{mi} .2008 .53$

10. Kaetzel CS. The polymeric immunoglobulin receptor: bridging innate and adaptive immune responses at mucosal surfaces. Immunol Rev. (2005) 206:8399. doi: 10.1111/j.0105-2896.2005.00278.x

11. Becker S, Oelschlaeger TA, Wullaert A, Pasparakis M, Wehkamp J, Stange EF, et al. Bacteria regulate intestinal epithelial cell differentiation factors both in vitro and in vivo. PLOS ONE. (2013) 8:e55620. doi: 10.1371/journal.pone.0055620

12. Eckmann L, Jung H, Schuerer-Maly C, Panja A, Morzycka-Wroblewska E, Kagnoff MF. Differential cytokine expression by human intestinal epithelial cell lines: regulated expression of interleukin-8. Gastroenterology. (1993) 105:1689-97. doi: 10.1016/0016-5085(93)91064-O

13. Gewirtz AT, Navas TA, Lyons S, Godowski PJ, Madara JL. Cutting edge: bacterial flagellin activates basolaterally expressed TLR5 to induce epithelial proinflammatory gene expression. J Immunol. (2001) 167:1882-5. doi: 10.4049/jimmunol.167.4.1882

14. Maresca M, Yahi N, Younès-Sakr L, Boyron M, Caporiccio B, Fantini J. Both direct and indirect effects account for the pro-inflammatory activity of enteropathogenic mycotoxins on the human intestinal epithelium: stimulation of interleukin- 8 secretion, potentiation of interleukin-1beta effect and increase in the transepithelial passage of commensal bacteria. Toxicol Appl Pharmacol. (2008) 228:84-92. doi: 10.1016/j.taap.2007.11.013

15. Ramos HC, Rumbo M, Sirard J-C. Bacterial flagellins: mediators of pathogenicity and host immune responses in mucosa. Trends Microbiol. (2004) 12:509-17. doi: 10.1016/j.tim.2004.09.002

16. Ukena SN, Singh A, Dringenberg U, Engelhardt R, Seidler U, Hansen W, et al. Probiotic Escherichia coli Nissle 1917 inhibits leaky gut by enhancing mucosal integrity. PLoS ONE. (2007) 2:e1308. doi: 10.1371/journal.pone.0001308

17. Uzal F, Vidal J, McClane B, Gurjar A. Clostridium perfringens toxins involved in mammalian veterinary diseases. Open Toxinol J. (2010) 2:24-42. doi: 10.2174/1875414701003020024

18. Macho Fernandez E, Fernandez EM, Valenti V, Rockel C, Hermann C, Pot B, et al. Anti-inflammatory capacity of selected lactobacilli in experimental colitis is driven by NOD2-mediated recognition of a specific peptidoglycanderived muropeptide. Gut. (2011) 60:1050-9. doi: 10.1136/gut.2010. 232918

19. Khokhlova EV, Smeianov VV, Efimov BA, Kafarskaia LI, Pavlova SI, Shkoporov AN. Anti-inflammatory properties of intestinal Bifidobacterium strains isolated from healthy infants. Microbiol Immunol. (2012) 56:27-39. doi: 10.1111/j.1348-0421.2011.00398.x
20. Lee J, Yang W, Hostetler A, Schultz N, Suckow MA, Stewart KL, et al. Characterization of the anti-inflammatory Lactobacillus reuteri BM36301 and its probiotic benefits on aged mice. BMC Microbiol. (2016) 16:69. doi: 10.1186/s12866-016-0686-7

21. FAO/WHO. Guidelines for the Evaluation or Probiotics in Food. Report of a Joint FAO/WHO Working Group on Drafting Guidelines for the evaluation of Probiotics in Food; Ontario, Canada (2002).

22. Huyghebaert G, Ducatelle R, van Immerseel F. An update on alternatives to antimicrobial growth promoters for broilers. Vet J. (2011) 187:182-8. doi: 10.1016/j.tvjl.2010.03.003

23. Rhayat L, Jacquier V, Géraert PA, Devillard E, Brinch KS, Nielsen P, et al. Bacillus subtilis strain specificity affects performance improvement in broilers. Poult Sci. (2017) 96:2274-80. doi: 10.3382/ps/pex018

24. Bambou JC, Giraud A, Menard S, Begue B, Rakotobe S, Heyman M, et al. In vitro and ex vivo activation of the TLR5 signaling pathway in intestinal epithelial cells by a commensal Escherichia coli strain. J Biol Chem. (2004) 279:42984-92. doi: 10.1074/jbc.M405410200

25. van de Walle J, Romier B, Larondelle Y, Schneider YJ. Influence of deoxynivalenol on NF-kappaB activation and IL-8 secretion in human intestinal Caco-2 cells. Toxicol Lett. (2008) 177:205-14. doi: 10.1016/j.toxlet.2008.01.018

26. Al-Sadi RM, Ma TY. IL-1beta causes an increase in intestinal epithelial tight junction permeability. J Immunol. (2007) 178:4641-9. doi: 10.4049/jimmunol.178.7.4641

27. Parikh AA, Salzman AL, Kane CD, Fischer JE, Hasselgren PO. IL-6 production in human intestinal epithelial cells following stimulation with IL-1 beta is associated with activation of the transcription factor NF-kappa B. J Surg Res. (1997) 69:139-44. doi: 10.1006/jsre.1997.5061

28. Schuerer-Maly CC, Eckmann L, Kagnoff MF, Falco MT, Maly FE. Colonic epithelial cell lines as a source of interleukin-8: stimulation by inflammatory cytokines and bacterial lipopolysaccharide. Immunology. (1994) 81:85-91.

29. Oeckinghaus A, Hayden MS, Ghosh S. Crosstalk in NF-kappaB signaling pathways. Nat Immunol. (2011) 12:695-708. doi: 10.1038/ni.2065

30. Liu T, Zhang L, Joo D, Sun S-C. NF-кB signaling in inflammation. Signal Transduct Target Ther.(2017) 2:17023.doi: 10.1038/sigtrans.2017.23

31. Morris KR, Lutz RD, Choi HS, Kamitani T, Chmura K, Chan ED. Role of the NF-kappaB signaling pathway and kappaB cis-regulatory elements on the IRF-1 and iNOS promoter regions in mycobacterial lipoarabinomannan induction of nitric oxide. Infect Immun.(2003) 71:144252. eng. doi: 10.1128/IAI.71.3.1442-1452.2003

32. Hughes JE, Srinivasan S, Lynch KR, Proia RL, Ferdek P, Hedrick CC. Sphingosine-1-phosphate induces an antiinflammatory phenotype in macrophages. Circ Res. (2008) 102:950-8. doi: 10.1161/CIRCRESAHA.107.170779

33. Maresca M, Miller D, Quitard S, Dean P, Kenny B. Enteropathogenic Escherichia coli (EPEC) effector-mediated suppression of antimicrobial nitric oxide production in a small intestinal epithelial model system. Cell Microbiol. (2005) 7:1749-62. doi: 10.1111/j.1462-5822.2005.00587.x

34. Graziani F, Pujol A, Nicoletti C, Pinton P, Armand L, Di Pasquale E, et al. The food-associated ribotoxin deoxynivalenol modulates inducible NO synthase in human intestinal cell model. Toxicol Sci. (2015) 145:372-82. doi: $10.1093 /$ toxsci/kfv058

35. Ruchaud-Sparagano M-H, Maresca M, Kenny B. Enteropathogenic Escherichia coli (EPEC) inactivate innate immune responses prior to compromising epithelial barrier function. Cell Microbiol. (2007) 9:1909-21. doi: 10.1111/j.1462-5822.2007.00923.x

36. Varini K, Benzaria A, Taieb N, Di Scala C, Azmi A, Graoudi S, et al. Mislocalization of the exitatory amino-acid transporters (EAATs) in human astrocytoma and non-astrocytoma cancer cells: effect of the cell confluence. $J$ Biomed Sci. (2012) 19:10. doi: 10.1186/1423-0127-19-10

37. Razafimanjato H, Benzaria A, Taïeb N, Guo X-J, Vidal N, Di Scala C, et al. The ribotoxin deoxynivalenol affects the viability and functions of glial cells. Glia. (2011) 59:1672-83. doi: 10.1002/glia.21214

38. Kim IB, Kim DY, Lee SJ, Sun MJ, Lee MS, Li H, et al. Inhibition of IL-8 production by green tea polyphenols in human nasal fibroblasts and A549 epithelial cells. Biol Pharm Bull. (2006) 29:1120-5. doi: 10.1248/bpb.29.1120

39. Ducatelle R, Goossens E, Meyer F, de Eeckhaut V, Antonissen G, Haesebrouck F, et al. Biomarkers for monitoring intestinal health in 
poultry: present status and future perspectives. Vet Res. (2018) 49:43. doi: 10.1186/s13567-018-0538-6

40. Gu MJ, Song SK, Park SM, Lee IK, Yun C-H. Bacillus subtilis protects porcine intestinal barrier from deoxynivalenol via improved zonula occludens-1 expression. Asian Australas J Anim Sci. (2014) 27:580-6. doi: 10.5713/ajas.2013.13744

41. Okumura R, Takeda K. Roles of intestinal epithelial cells in the maintenance of gut homeostasis. Exp Mol Med. (2017) 49:e338. doi: 10.1038/emm.2017.20

42. Hosoi T, Hirose R, Saegusa S, Ametani A, Kiuchi K, Kaminogawa S. Cytokine responses of human intestinal epithelial-like Caco-2 cells to the nonpathogenic bacterium Bacillus subtilis (natto). Int J Food Microbiol. (2003) 82:255-64. doi: 10.1016/S0168-1605(02)00311-2

43. McAlindon ME, Hawkey CJ, Mahida YR. Expression of interleukin 1 beta and interleukin 1 beta converting enzyme by intestinal macrophages in health and inflammatory bowel disease. Gut. (1998) 42:214-9. doi: 10.1136/gut.42.2.214

44. Sokol H, Pigneur B, Watterlot L, Lakhdari O, Bermúdez-Humarán LG, Gratadoux J-J, et al. Faecalibacterium prausnitzii is an antiinflammatory commensal bacterium identified by gut microbiota analysis of Crohn disease patients. Proc Natl Acad Sci USA. (2008) 105:16731-6. doi: $10.1073 /$ pnas. 0804812105

45. Heuvelin E, Lebreton C, Grangette C, Pot B, Cerf-Bensussan N, Heyman $\mathrm{M}$, et al. Mechanisms involved in alleviation of intestinal inflammation by bifidobacterium breve soluble factors. PLoS ONE. (2009) 4:e5184. doi: 10.1371/journal.pone.0005184

46. Akbarian A, Michiels J, Degroote J, Majdeddin M, Golian A, De SS. Association between heat stress and oxidative stress in poultry; mitochondrial dysfunction and dietary interventions with phytochemicals. J Anim Sci Biotechnol. (2016) 7:1-14. doi: 10.1186/s40104-016-0097-5

47. Ottman N, Reunanen J, Meijerink M, Pietilä TE, Kainulainen V, Klievink J, et al. Pili-like proteins of Akkermansia muciniphila modulate host immune responses and gut barrier function. PLoS ONE. (2017) 12:e0173004. doi: 10.1371/journal.pone.0173004

48. Chon H, Choi B, Lee E, Lee S, Jeong G. Immunomodulatory effects of specific bacterial components of Lactobacillus plantarum KFCC11389P on the murine macrophage cell line RAW 264.7. J Appl Microbiol. (2009) 107:1588-97. doi: $10.1111 /$ j.1365-2672.2009.04343.x
49. Jacquier V, Nelson A, Jlali M, Rhayat L, Brinch KS, Devillard E. Bacillus subtilis 29784 induces a shift in broiler gut microbiome toward butyrateproducing bacteria and improves intestinal histomorphology and animal performance. Poultry Sci. (2019) doi: 10.3382/ps/pey602. [Epubh ahead of print].

50. Lee K, Lillehoj HS, Siragusa GR. Direct-fed microbials and their impact on the intestinal microflora and immune system of chickens. J Poult Sci. (2010) 47:106-14. doi: 10.2141/jpsa.009096

51. Rajput IR, Li LY, Xin X, Wu BB, Juan ZL, Cui ZW, et al. Effect of Saccharomyces boulardii and Bacillus subtilis B10 on intestinal ultrastructure modulation and mucosal immunity development mechanism in broiler chickens. Poult Sci. (2013) 92:956-65. doi: 10.3382/ps.2012-02845

52. Lee K-W, Kim DK, Lillehoj HS, Jang SI, Lee S-H. Immune modulation by Bacillus subtilis-based direct-fed microbials in commercial broiler chickens. Animal Feed Sci Technol. (2015) 200:76-85. doi: 10.1016/j.anifeedsci.2014.12.006

53. Wang WC, Yan FF, Hu JY, Amen OA, Cheng HW. Supplementation of Bacillus subtilis-based probiotic reduces heat stress-related behaviors and inflammatory response in broiler chickens1. J Anim Sci. (2018) 96:1654-66. doi: 10.1093/jas/sky092

Conflict of Interest Statement: LR, EE, and ED are employed by Adisseo France SAS. KB and SC are employed by Novozymes A/S. Adisseo France SAS and Novozymes S/A jointly commercialize Bacillus strain Bs 29784.

The remaining authors declare that the research was conducted in the absence of any commercial or financial relationships that could be construed as a potential conflict of interest.

Copyright $\odot 2019$ Rhayat, Maresca, Nicoletti, Perrier, Brinch, Christian, Devillard and Eckhardt. This is an open-access article distributed under the terms of the Creative Commons Attribution License (CC BY). The use, distribution or reproduction in other forums is permitted, provided the original author(s) and the copyright owner(s) are credited and that the original publication in this journal is cited, in accordance with accepted academic practice. No use, distribution or reproduction is permitted which does not comply with these terms. 